\title{
Microstructure evolution of Al-7wt \%Si-2wt\%Fe alloy processed by high-pressure torsion
}

\author{
Jittraporn Wongsa-Ngam ${ }^{1, *}$, Chakkrist Phongphisutthinan ${ }^{2}$, and Terence G. Langdon ${ }^{3}$ \\ Mechanical Engineering Department, Faculty of Engineering, King Mongkut's Institute of Technology Ladkrabang, Bangkok,10520, \\ Thailand National Metal and Materials Technology Development Agency, National Science and Technology Development Agency, Bangkok, \\ 12120, Thailand \\ ${ }^{3}$ Materials Research Group, Faculty of Engineering and the Environment, University of Southampton, Southampton SO17 1BJ, United \\ Kingdom
}

\begin{abstract}
The microstructure evolution of an aluminum silicon-based alloy after severe plastic deformation processing was examined. An aluminum silicon-based alloy; Al- $7 \mathrm{wt} \% \mathrm{Si}-2 \mathrm{wt} \% \mathrm{Fe}$, was processed by the severe plastic deformation technique called high-pressure torsion at room temperature under a high pressure of $6.0 \mathrm{GPa}$ and rotational speed of $1.0 \mathrm{rpm}$ with numbers of revolution up to 5 turns. Microstructure evolution, especially intermetallic phase, was observed using an optical microscope and a scanning electron microscope (SEM). The effects of high-pressure torsion on the Fe intermetallic compounds in Al-Si alloy were investigated. It was found that the intermetallic particles decreased in size with increasing imposed strains.
\end{abstract}

\section{Introduction}

Severe Plastic Deformation (SPD) is a well-established technique for producing bulk ultrafine-grained (UFG) metallic materials [1]. In SPD processing, materials are subjected to the imposition of very large strains without the introduction of any concomitant changes in the crosssectional dimensions of the samples leading to superior properties [2]. In addition, the unusual phase transformations in SPD processing results in development of highly metastable states associated with the formation of supersaturated solid solutions, disordering or amorphization [3]

Aluminum alloys are widely used in modern engineering structures and components because of light weight and corrosion resistance. The most important cast aluminum alloy system is $\mathrm{Al}-\mathrm{Si}$, where the high levels of silicon contribute to give good casting characteristics. Al-Si-based casting alloys are interesting materials in the automotive and aerospace applications because of their low density, low thermal expansion coefficient and high wear resistance. However, Al-Si alloys exhibit low ductility and toughness that limit their applications. Previous studies demonstrated that severe plastic deformation processing applied to $\mathrm{Al}-\mathrm{Si}$ alloy has a potential for producing a homogenous microstructure and refinement leading to improvement of the mechanical properties [4-6]. The influence of a rotarydie ECAP method on $\mathrm{Al}-\mathrm{Si}$ alloys (11-23 wt.\% Si) are possible to refine the size of the Si particles and this leads to a large improvement in ductility, toughness and wear resistance but little strengthening [7-10].
Remarkable refinement of coarse $\mathrm{Si}$ particles of $\mathrm{Al}-7$ wt.\% Si was achieved through five turns of HPT [11]. Furthermore, stable fine particles can also improve thermal stability of the UFG microstructure through inhibiting grain growth [12]

In addition, iron is a common impurity in aluminum alloys that arises from a number of possible sources, especially; in secondary aluminum i.e. aluminum recycling. This impurity causes both positive and negative influences. Fe alloying into aluminum alloys has a potential as an inexpensive alloying element for strengthening. However, due to its low solubility in Al, Fe may be present as secondary phases in the form of intermetallics. The iron-containing intermetallics participate directly in the fracture mechanism, the more intermetallics there are, the lower the ductility. In addition, as the iron level increases, porosity also increases, and this type of casting defect also has a significant impact to ductility [13]. In general, $\mathrm{Fe}$ contents are strictly controlled to be low in commercial alloys, depending on the required applications. In recent years, the capability of producing bulk Al-Fe alloys with supersaturation of $\mathrm{Fe}$ by HPT processing has been reported in a cast $\mathrm{Al}-11 \% \mathrm{Fe}$ alloy [14]. The study on a cast $\mathrm{Al}-5$ wt.\% $\mathrm{Fe}$ subjected to ECAP processing reported grain refinement of the $\mathrm{Al}$ matrix and dispersion of second-phase particles so that the process led to the improvement of not only the microhardness but also the tensile strength and ductility [15].

The use of severe plastic deformation (SPD) to refine the secondary phase/intermetallic phase is interesting research, especially; the application of SPD to secondary

\footnotetext{
Corresponding author: jittraporn.wo@,kmitl.ac.th
} 
aluminum alloys from recycle where coarse intermetallic particles occur. In this study, the high-pressure torsion (HPT) processing was applied for Al-Si based alloys with 2 wt. $\%$ Fe to examine the microstructural evolution.

\section{Experimental materials and procedure}

The materials used in this investigation were $\mathrm{Al}-7 \% \mathrm{Si}$ $2 \% \mathrm{Fe}$ (in wt.\%) supplied by MTEC. They were prepared by casting of commercial A356 alloy billets and iron nail. A356 billets were melted at $800{ }^{\circ} \mathrm{C}$ for $2 \% \mathrm{Fe}$ alloy. Then iron nails were added and isothermally held for 2 $\mathrm{h}$. The molten aluminum was stirred every $30 \mathrm{~min}$ during casting after degasing by Nitrogen gas. Then, $1.3 \mathrm{~kg}$ molten aluminum ingot was cast into a steel mold and air cooled. The chemical compositions of A356 and the Al$7 \mathrm{wt} \% \mathrm{Si}-2 \mathrm{wt} \% \mathrm{Fe}$ are given in Table 1 . Before HPT the ingots were machined into billets with diameters of 10 $\mathrm{mm}$ and lengths of $70 \mathrm{~mm}$ and cut into disks with diameters of $10 \mathrm{~mm}$ and polished to final thicknesses of $\sim 0.83 \mathrm{~mm}$.

Table 1. Chemical compositions of aluminum alloy

\begin{tabular}{|l|l|l|l|l|l|l|}
\hline$(\mathrm{wt} \%)$ & $\mathrm{Si}$ & $\mathrm{Fe}$ & $\mathrm{Mg}$ & $\mathrm{Ti}$ & $\mathrm{Cr}$ & $\mathrm{Al}$ \\
\hline $\mathrm{A} 356$ & 7.035 & 0.096 & 0.442 & 0.103 & 0.018 & Bal. \\
\hline Al-7Si-2Fe & 6.819 & 2.160 & 0.384 & 0.101 & 0.016 & Bal. \\
\hline
\end{tabular}

The disks were processed using high-pressure torsion (HPT) [16]. The HPT processing was conducted under quasi-constrained conditions $[17,18]$ using a facility consisting of upper and lower anvils having central depressions with diameters of $10 \mathrm{~mm}$ and depths of 0.25 $\mathrm{mm}$. Each disk was placed in the central depression of the lower anvil and this anvil was then brought into position so that a pressure was applied on the disk. Torsional straining was achieved by rotation of the lower anvil at a constant speed of $1 \mathrm{rpm}$. In quasi-constrained HPT, there is a small outflow of material around the peripheries of the disks between the two anvils during the straining operation. All processing by HPT was conducted at room temperature using an applied force of $470 \mathrm{kN}$ which corresponds to an imposed pressure, $P$, of $6.0 \mathrm{GPa}$ with total straining through $1 / 4,2$ and 5 turns.

The samples were molded in plastic resins for grinding and polishing. The samples were ground with abrasive papers of silicon carbide ( $\mathrm{SiC}$ ) from 180 to 2500 grits subsequent to polishing with diamond powders of 3 and $1 \mu \mathrm{m}$ on micro-cloths. The sample surface was finished with chemical etching with a suitable etching reagent. After sample preparation, microstructure evolutions were observed by a scanning electron microscope (SEM) operating at an accelerating voltage of $20 \mathrm{kV}$.

\section{Results and discussion}

\subsection{Microstructure}

A commercial A356 alloy belongs to a group of hypoeutectic aluminum-silicon alloys. This as-cast A356 exhibited a typical hypoeutectic solidification structure, consisting of a primary aluminum matrix surrounded by the eutectic network structure as shown in Fig. 1. Iron impurities in the alloy led to the formation of a small amount of iron intermetallic compounds beta phase, $\beta$ $\mathrm{Al}_{5} \mathrm{FeSi}$ in a form of long platelet and alpha phase $\alpha$ $\mathrm{Al}_{8} \mathrm{Fe}_{2} \mathrm{Si}$ in a form of Chinese script.

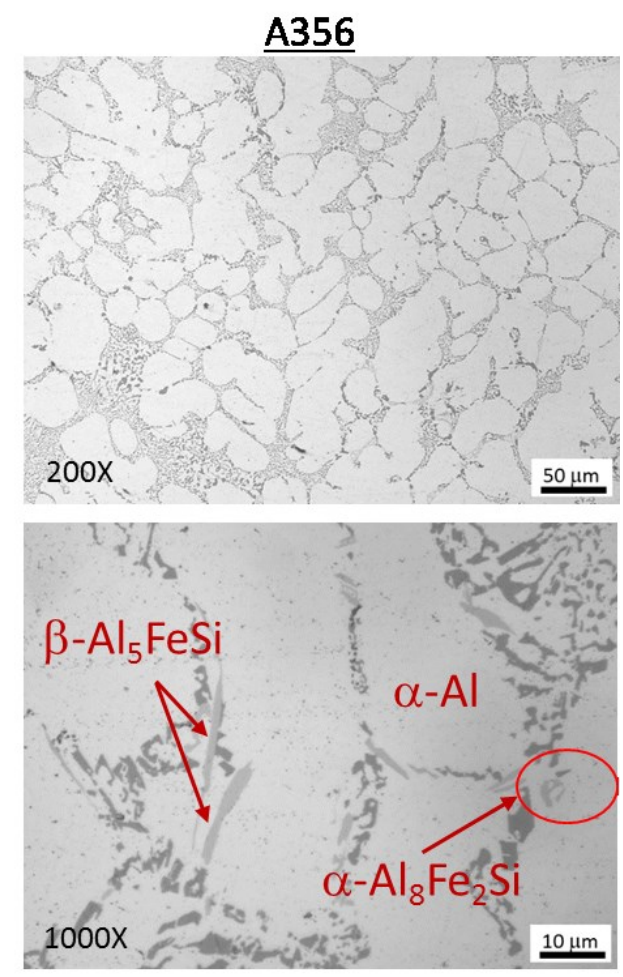

Fig.1. Microstructure of commercial A356 alloy.

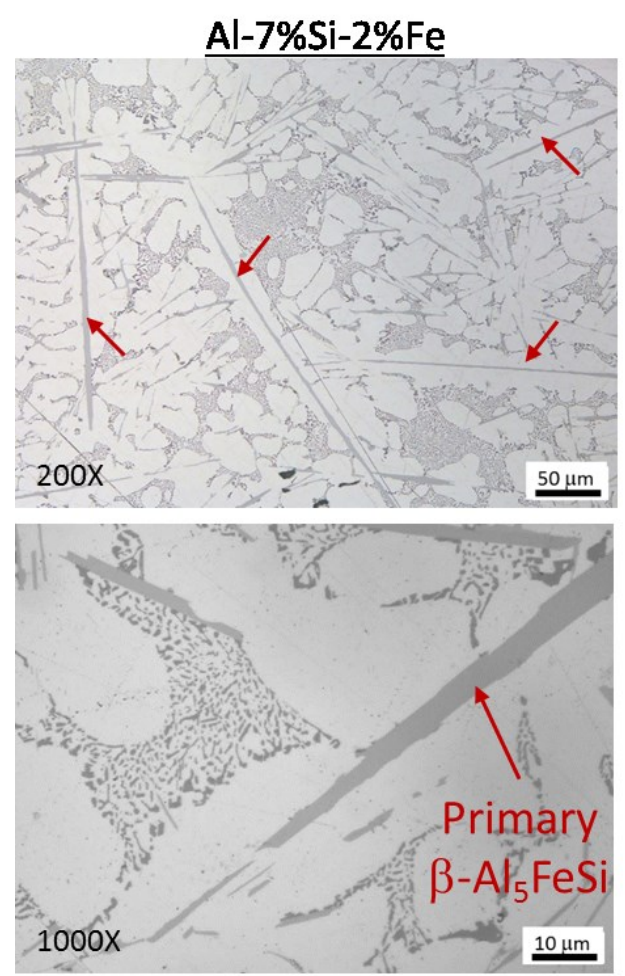

Fig. 2. The microstructure of $\mathrm{Al}-7 \mathrm{wt} \% \mathrm{Si}-2 \mathrm{wt} \% \mathrm{Fe}$ before HPT processing 
With increasing the Fe-content to $2 \mathrm{wt} \%$, $\mathrm{Al}-7 \mathrm{wt} \% \mathrm{Si}$ $2 \mathrm{wt} \% \mathrm{Fe}$ alloy, results in the earlier formation of the dominant intermetallic phases and more unconstrained growth of particles. As shown in Fig. 2 the size of intermetallic $\beta$-phase is larger and longer and the fraction of intermetallic phase also increases in this material composition. It should be noted that the large and long particles cause negative effects to failure in which the failure propagation occurs easily.

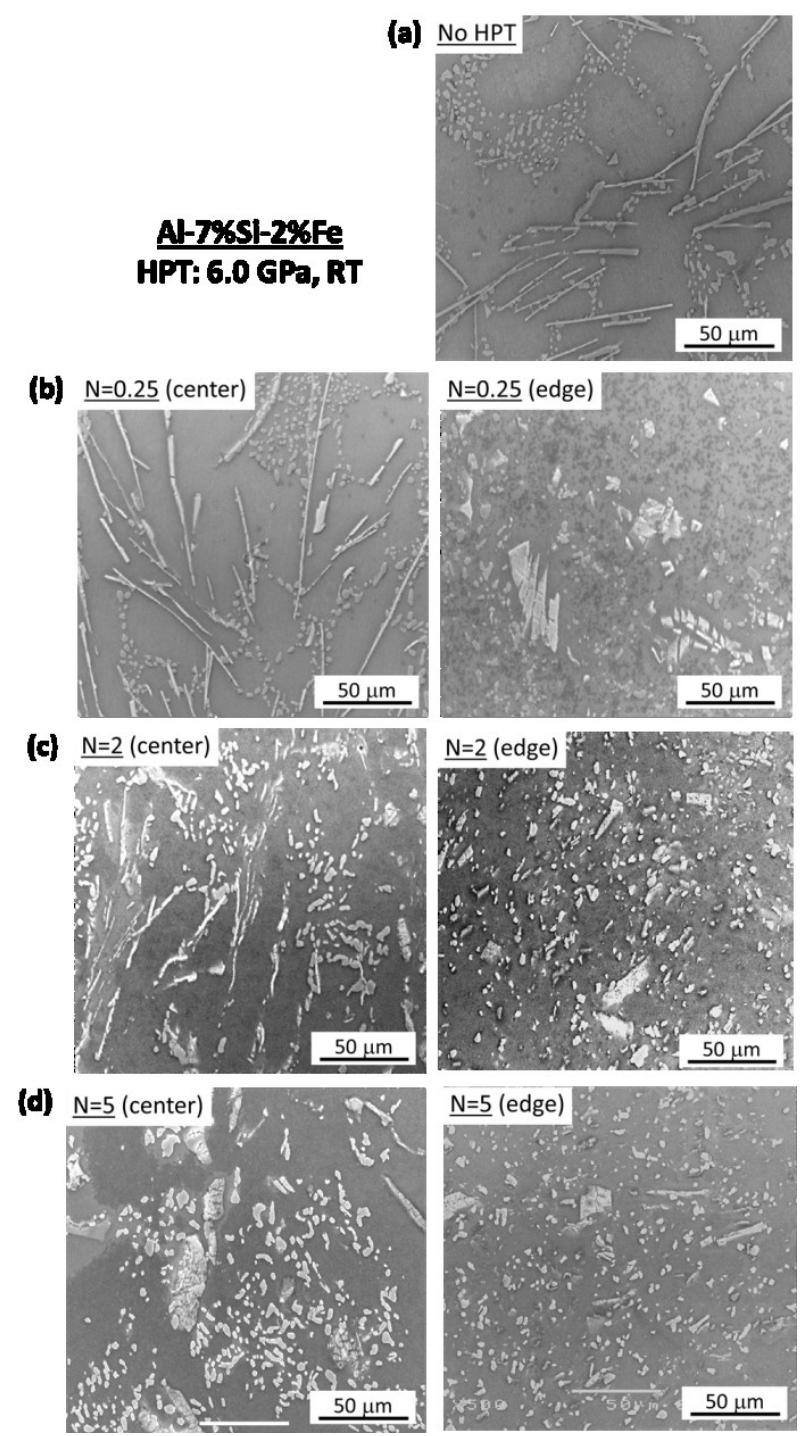

Fig.3. The microstructure of $\mathrm{Al}-7 \mathrm{wt} \% \mathrm{Si}-2 \mathrm{wt} \% \mathrm{Fe}$ in (a) as-cast sample (b) after HPT 1/4 turn (c) after HPT 2 turns and (d) after HPT 5 turns

The microstructures of samples after HPT were analysed in two regions; center and edge because shear strain introduced by HPT processing is a function of not only a number of turns $N$, but also the distance from the disk center $r$ and the thickness $t$ as following the relationship for equivalent strain [19]:

$$
\varepsilon=\frac{2 \pi N r}{\sqrt{3} t}
$$

After a quarter turn of HPT processing (Fig. 3(b)), there is a different microstructure at central and edge region because of the variation of imposed strain as a function of disk radius $r$, in Eq. (1). The microstructure on central area of the specimen closely resembles that in the as-cast specimen without HPT processing in Fig. 3(a). However, there is a significant change near the edge of a disk because of the higher strains imposed that cause fragmentation of intermetallic particles.

After two turns (Fig. 3(c)), in the central area the long shape of $\beta$-phase become broken but the distribution remains inhomogeneous. Near the edge region of sample, intermetallic particles become fragmented to small size. The distribution of particles is quite homogeneous.

After five turns (Fig.3(d)), the intermetallic particles in the central region are continuously refined but the intermetallic particle are not homogeneously distributed. The microstructure near the edge after five turns is similar to the microstructure after two turns.

This results show that HPT processing has a potential to refine the intermetallic phases for the $\mathrm{Al}-7 \mathrm{wt} \% \mathrm{Si}$ $2 \mathrm{wt} \% \mathrm{Fe}$ alloy; which is representative of recycled aluminum alloys.

In future research, the effect of dispersion of secondphase particles on mechanical property improvement for Al- $7 \% \mathrm{Si}-2 \% \mathrm{Fe}$ alloy after HPT processing will be studied.

\section{Summary and conclusions}

1. Al-Si-Fe alloy was subjected to large strain by highpressure torsion (HPT) processing at room temperature under pressure of $6.0 \mathrm{GPa}$ with different numbers of turns of $1 / 4,2$ and 5 turns

2. The effects of HPT on intermetallic particles of Aluminum-Silicon-Iron were investigated.

3. The microstructure evolution and intermetallic refinement during high-pressure torsion processing occur by introducing a large amount of plastic strain.

4. The large strains introduced by HPT at ambient temperature cause fragmentation of iron-intermetallic particles. The degree of fragmentation increases with increasing strains

5. The microstructure results demonstrate that the intermetallic particles decreased in size with increasing imposed strains.

\section{Acknowledgement}

We would like to acknowledge financial support of the KMITL Research Fund under project number KREF01590.

\section{References}

1. R.Z. Valiev, R.K. Islamgaliev, I.V. Alexandrov, Prog. Mater. Sci. 45 (2000) 103. 
2. Y.T. Zhu, T.C. Lowe, T.G. Langdon, Scripta Materialia 51 (2004) 825.

3. R.Z. Valiev, Adv. Eng. Mater. 5 (2003) 296.

4. A. Ma, N. Saito, M. Takagi, Y. Nishida, H. Iwata, K. Suzuki, I. Shigematsu, A. Watazu, Mater. Sci. Eng. A 395 (2005) 70.

5. Y. Kume, M. Kobashi, N. Kanetake, Aluminium Alloys 519-521 (2006) 1441, Parts 1 and 2

6. Z.Y. Ma, S.R. Sharma, R.S. Mishra, Scripta Mater. 54 (2006) 1623.

7. A. Ma, K. Suzuki, Y. Nishida, N. Saito, I. Shigematsu, M. Takagi, et al. Acta Mater. 53 (2005) 211.

8. A. Ma, K. Suzuki, N. Saito, Y. Nishida, M. Takagi, I. Shigematsu, et. al. Mater. Sci. Eng. A 399 (2005) 181.

9. A. Ma, M. Takagi, N. Saito, H. Iwata, Y. Nishida, K. Suzuki, et. al. Mater. Sci. Eng. A 408 (2005) 147

10. Z. Zhang, S. Hosoda, I-S. Kim, Y. Watanabe, Mater. Sci. Eng. A 425 (2006) 55.

11. A.P. Zhilyaev, J.M. Garcia-Infanta, F. Carreno, T.G. Langdon, O.A. Ruano, Scripta Mater. 57 (2007) 763

12. K. Oh-ishi, Z. Horita, D.J. Smith, T.G. Langdon, J. Mater. Res. 16 (2001) 583.

13. J.A. Taylor, Procedia Mater. Sci. 1 (2012) 19-23.

14. O.N. Senkov, F.H. Froes, V.V. Stolyarov, R.Z. Valiev, J. Liu, Nanostruct. Mater.10 (1998) 691.

15. V.V. Stolyarov, R. Lapovok, I.G. Brodova, P.F. Thomson, Mater. Sci. Eng. A 10 (2003) 159.

16. A.P. Zhilyaev, T.G. Langdon, Prog. Mater. Sci. 53 (2008) 893.

17. R.B. Figueiredo, P.R. Cetlin, T.G. Langdon, Mater. Sci. Eng. A 528 (2011) 8198.

18. R.B. Figueiredo, P.H.R. Pereira, M.T.P. Aguilar, P.R. Cetlin, T.G. Langdon, Acta Mater. 60 (2012) 3190.

19. R.Z. Valiev, Y. Estrin, Z. Horita, T.G. Langdon, M.J. Zehetbauer, Y.T. Zhu : JOM 58 (4) (2006) 33. 